\title{
THE PERFORMANCE OF STUTTERERS ON SELECTED CENTRAL AUDITORY TESTS
}

\author{
GABRIELLE M. KARR B.A. (SP. \& H. THERAPY) (WITWATERSRAND) \\ Psychological and Guidance Services, \\ Transvaal Education Dept., Johannesburg
}

\begin{abstract}
SUMMARY
The possibility of central auditory involvement in stutterers was investigated. Five confirmed stutterers and five nonstutterers between the ages of 20 and 26 years served as subjects. The Phonetically Balanced CID W-22 Auditory Lists presented with ipsilateral and cont ralateral white noise broad band masking (at signal to noise ratios of $0 \mathrm{~dB}$ and $-10 \mathrm{~dB}$ ) and the Staggered Spondaic Word Test were utilized. No significant differences between the groups were revealed, indicating intact functioning of both groups on these tests. Possible reasons for this were postulated. Response trends exhibited by all subjects were discussed.
\end{abstract}

\section{OPSOMMING}

Hierdie studie beoog om moontlike sentraal-ouditiewe betrokkenheid in hakkelaars te ondersoek. Vyf gevestigde hakkelaars en vyf nie-hakkelaars tussen die ouderdomme van 20 en 26 jaar is as proefpersone gebruik. Die Foneties Gebalanseerde CID W-22 Ouditiewe Lyste, aangebied met ipsilaterale en kontralaterale wit lawaai breë-band maskering (teen sein tot ruis verhouding van $0 \mathrm{~dB}$ en - $10 \mathrm{~dB}$ ), en die Verspringende Spondee Woordtoets (VSW) is benuttig. Geen merkbare verskille is tussen die groepe gevind nie. Hierdie resultate dui ongeskonde funksionering betreffende hierdie toetse vir altwee groepe aan. Moontlike redes hiervoor is gepostuleer. Responsneigings van al die proefpersone is besprèek.

Many hypotheses concerning the etiology of stuttering have been postulated. Sander ${ }^{25}$ summarized the causation areas of stuttering considered in the literature as those of reinforced behaviour, emotion and organicity. The latter model is relevant to the present study.

Within the framework of the possibility of an organic component in stuttering, a neurological involvement has been suggested. The Orton-Travis Theory of Cerebral Dominance (1931) postulated that due to a lack of maturation in the cortical speech areas, intercerebral hemisphere conflict occurs - cerebral dominance does not develop and stuttering results. ${ }^{4}$ Progress in testing methods and subsequent physiological findings led to the rejection of this theory. Nevertheless an interest in it persists. Jones ${ }^{9}$ using the Wada-Rasmussen Sodium Amytol technique, concluded that stutterers do exhibit intercerebral conflict for speech, but controversial findings have been reported. Similarly, the performance of stutterers on dichotic tests, (which assess temporal lobe functioning ${ }^{11}$ ) is held in question. ${ }^{9,27,32}$ In addition, the hypothesis that stuttering is a sub-class of aphasia ${ }^{36}$ indicates that temporal lobe functioning in stutterers needs to be clarified. 
Wolf and Wolf ${ }^{8}$ suggested that a brainstem lesion results in stuttering and the performance of stutterers on the Synthetic Sentence Identification Test with an ipsilateral competing message (a test reported to be sensitive to brainstem lesions ${ }^{11}$ ) was reported to be inferior to that of nonstutterers. ${ }^{31}$ However, further investigation to support or refute the existence of brainstem lesions in stutterers, is indicated.

The auditory cortex consists of the primary and secondary auditory areas. Stimulation of the former produces the sensation of hearing non-verbal sounds, ${ }^{22}$ while stimulation of the latter evokes the sensation of hearing verbal signals ${ }^{17}$ and thus participate in speech decoding. The secondary auditory cortex, lying in the lateral convex portions of the temporal lobe, is thought to be responsible for the analysis and synthesis of acoustic stimuli and differentiates between simultaneously presented acoustic information. ${ }^{17}$ The interaction of the higher brainstem and the dominant tempero-parieto-occipital region enables speech comprehension. ${ }^{22}$ The secondary auditory areas and the post central and premotor articulation areas are connected by U-shaped structures and are within the subcortical gray matter of the cortex, ${ }^{17}$ thus revealing the reality of neurological connections between the speech and auditory systems.

A central disorder has been defined as an . . . impairment of the cerebral cortex and subcortical areas, probably to the level of the brainstem ${ }^{14}$ so that primary sites of a central auditory system (CAS) lesion may be considered to be in the brainstem or in Heschl's gyrus. " This study is concerned with the functioning of these two areas in stutterers. Lesions at these sites do not lead to impaired scores on conventional pure-tone or speech audiometric tests. ${ }^{s, 11}$ The use of speech has been favoured in CAS testing as the functions of discrimination and integration and the participation of the language processess are tapped. ${ }^{5}$ The probability rules of redundancy and predictability involved in speech perception had to be eliminated and thus the speech material utilized in CAS tests had to be suitably selected.

Tests such as the Speech with Alternating Masking Index (SWAMI) ${ }^{35}$ and fusion tests ${ }^{5}$ have been utilized in brain stem lesion testing and Jerger ${ }^{11}$ suggests that individuals with brainstem involvement have greater difficulty with a complex monaural task than a dichotic task. The use of ipsilateral masking has been suggested as a factor which increases the complexity of speech identification tasks. ${ }^{5}$ Dichotic tests have been used in evaluating temporal lobe functioning. ${ }^{35}$ A dichotic task may be viewed as one involving simultaneous sets of information being presented to each ear. The Staggered Spondaic Word Test (SSW) devised by Katz ${ }^{13}$ is partially dichotic and is reportedly a CAS test sensitive to temporal lobe lesions. ${ }^{6}$ The performance of normals on dichotic tasks reveal superior Right Ear performance which is known as the Right Ear Affect (REA), and reduced scores in the ear contralateral to a CAS lesion have been reported on dichotic tasks. ${ }^{9}$ The SSW yields Right and Left Ear scores and it may therefore reveal differences in ear performance in stutterers as compared to nonstutterers. 


\section{METHODOLOGY}

It was hypothesized that the performance of stutterers on a brainstem and/or temporal lobe CAS test would be inferior to that of nonstutterers. Inferior performance by the stutterers will be reflected by decreased ear difference scores as compared to the scores of the nonstutterers.

\section{SUBJECTS.}

Two groups of Subjects (Ss) were selected:

Group E consisted of five stutterers. Group C comprised five nonstutterers.

\section{Criteria for Subject Selection.}

1. Age: All Ss were between twenty and twenty-six years of age - to exclude the possibility of the changing 'stuttering mechanisms' of adolescence, and in view of the documented reliability of the SSW with 11-60 year olds. ${ }^{6}$

2. Home Language: The home language of all Ss is South African English to prevent the influence of unfamiliarity with the language affecting performance.

3. Intelligence: Ss with average intelligence were utilized - to eliminate contamination by the suggested relationship between intelligence and auditory abilities. ${ }^{5}$ All Ss were studying at post-matriculation levels.

4. Handedness: Only Right handed Ss were utilized as most stutterers are reportedly Right handed ${ }^{4}$ and in view of the theory that a correlation between ear, brain and hand dominance exists. ${ }^{26}$

5. Peripheral Hearing Status: All Ss were required to have pure tone thres. holds within normal limits and no otological involvement at the time of testing.

6. Sex: Each group consisted of one female and four males, as the reported ratio of male to female stutterers at the American 'college' level has been found to be $1,6-3,4: 1$. $^{30}$

7. Neurological Status: As the presence of gross.neurological lesions would have biased results, their absence in all Ss served as a further selection factor.

\section{TESTS AND PROCEDURE}

Selection Procedures.

(a) Speech Task (for Group E): In order to be included in this study nonfluencies as described by Johnson et al ${ }^{12}$ had to be present in the speech of Group E on a propositional task.

(b) Handedness Test: A handedness test based on that of Satz et al ${ }^{26}$ was administered. Subjects had to be Right handed to be included in this study.

(c) Pure-Tone Air-Conduction Threshold Test: Thresholds were established in the conventional manner. 


\section{Audiological Tests.}

\section{A. Pretests:}

Speech Reception Threshold Test (SRT): Written responses were required for this and all subsequent tests in view of the speech difficulty of Group E.

Speech Discrimination Test: Half lists of Phonetically Balanced words, the CID Word List W-22 (PB CID W-22) were utilized in obtaining speech discrimination scores at $50 \mathrm{~dB}$ SL for each ear. Testing and scoring were carried out in the conventional manner. ${ }^{20}$

B. Central Auditory Tests:

The order of presentation of the central tests was randomized to prevent fatigue and learning from influencing results.

(a) Phonetically Balanced CID W.22 with contralateral and ipsilateral masking at Signal to Noise ratios of $0 \mathrm{~dB}$ and $-10 \mathrm{~dB}$.

It has been reported that ipsilateral masking with $\mathrm{PBs}$ is a test sensitive to central disorders ${ }^{18}$ and the use of monaural tasks in brain stem testing. has been suggested. ${ }^{11}$ The sub-test, including contralateral masking thus served as a basis of comparison. Results of previous investigations indicate a greater breakdown in speech discrimination at a signal to noise (SN) ratio of greater than $-5 \mathrm{~dB}$ than at $0 \mathrm{~dB} \cdot{ }^{37}$ As complexity of central tests has been stressed ${ }^{5}$ a $\mathrm{SN}$ ratio of $-10 \mathrm{~dB}$ was incorporated, while the sub-test at the $\mathrm{SN}$ ratio of $0 \mathrm{~dB}$ was utilized to serve as a basis of comparison. All sub-tests were administered at $50 \mathrm{~dB}$ SL.

White noise was utilized as it has been reported to be the most effective form of masking noise for speech. ${ }^{20}$ PB CID W-22 half lists were utilized to prevent fatigue on the part of $\mathrm{S}$. Conventional instructions and scoring procedures were employed. 2,20

(b) The Staggered Spondaic Word Test.

The SSW, reportedly a test of temporal lobe functioning, ${ }^{6}$ was administered at $50 \mathrm{~dB}$ SL to each ear. An American recording of the SSW test list EC was utilized which consists of four practice items and 40 test items. Each test item consists of two overlapping spondees, one presented to each ear, arranged so that the last syllable of the first spondee and the first syllable of the second spondee overlap in time. The non-competing syllables form a third spondee. Presentation of the first syllable alternates between the ears and is preceded by 'Are you ready?' Preceding the test is a recorded $1000 \mathrm{~Hz}$ tone in each channel allowing for calibration. Katz's ${ }^{6}$ system of weighting was employed in scoring the tests, but all faulty responses, even if minimal, were considered as errors. ${ }^{1}$

\section{EQUIPMENT}

Audiological assessments were carried out in an I.A.C. Acoustic suite (Series 1600) utilizing the Maico Model MA-24 dual channel audiometer. The speech material was routed to this audiometer from a Viking 88 stereo tape recorder. 


\section{RESULTS AND DISCUSSION}

No significant differences in performance between Group E and Group C were found on both central tests utilized.

Nevertheless performance of all Ss taken as one group revealed several trends. Discussion of the trends and observations made on the brainstem test will be followed by that of the temporal lobe test.

(a)PB CID W-22 with ipsilateral and contralateral masking at SN ratios of 0 $\mathrm{dB}$ and $-10 \mathrm{~dB}$. The following trends were noted for the $\mathrm{Ss}$, taken as one group:

1. Ipsilateral masking sub-tests yielded significantly fewer correct responses than contralateral masking ( $p<0,001)$, validating the former's greater complexity. A similar finding is reported for performance on the SWAMI, a test reportedly sensitive to brainstem lesions. ${ }^{35}$

2. Significantly fewer correct responses occurred when the masking, whether ipsilateral or contralate ral, was $10 \mathrm{~dB}$ SL louder than the speech signal as opposed to speech and masking of equal $S L s(p<0,001)$. This supports the conclusion that discrimination scores decrease as the $\mathrm{SN}$ ratio decreases. ${ }^{10}$

3. No ear differences occurred on the contralateral masking sub-tests while significantly fewer correct responses in the left ear occurred under the conditions of ipsilateral masking $(0,025<p .<0,05)$ indicating that performance in the right ear was similar for both contralateral and ipsilateral masking sub-tests, while in the left ear, inferior performance under the ipsilateral masking condition occurred. Performance on the contralateral masking condition was similar to that of the right ear. Thus the process of transmission and figure-ground differentiation for speech appears to be more efficient when stimuli are presented to the right ear, which connects, by way of its strong contralateral pathway, to the left hemisphere which is dominant for speech. ${ }^{15}$ The strong contralateral pathway from the left ear leads to the right hemisphere which is dominant for nonspeech sounds. ${ }^{21}$ Masking may be considered as one type of non-speech sound.

Speech and noise may be differentiated at the brainstem, whereafter the speech is transmitted to the left (speech) hemisphere, but if the brainstem does not function in this process, differentiation may only occur at the cortex where the rate of spontaneous activity and the quantity of discharged impulses are less than at the brain stem, 10,23 thus placing the speech message transmitted from the left ear at a disadvantage. If this latter suggestion is to be adopted however, the validity of this test as a brainstem test is to be questioned. Other limitations of this test may serve as further factors querying its validity as a brainstem test. For example, the necessity for central tests to be complex tasks has been discussed. The mere addition of masking noise may not have increased the complexity of this task sufficiently for it to assess brainstem functioning. 
(b) The Staggered Spondaic Word Test.

The following trends were noted for the Ss taken as one group.

1. Significantly more errors occurred on competing than non-competing syllables $(0,025<\mathrm{p}<0,01)$ confirming the greater complexity of dichotically than monotically presented material.

2. While performance on non-competing syllables was similar for both ears, the left ear showed significantly greater difficulty for competing stimuli than the right ear $(p=0,05)$. Under competing conditions the REA discussed earlier may thus be considered to have occurred and, as no differences between Group $E$ and Group $C$ were evident, no difference in the dominance between the stutterers and non-stutterers in this experiment was seen to exist - casting doubt on the applicability of the Orton-Travis Theory to these stutterers. It has nevertheless been claimed that the SSW is 'free' from laterality effects. ${ }^{6}$ If this holds true, the true dichotic properties of the SSW are to be questioned. The present study does however indicate the presence of the REA in the SSW.

The true dichotic properties of the SSW are to be further questioned however. Familiarity and word probability introduce the variable of redundancy, and, in central testing the necessity of reduced redundancy has been stressed. Although Katz ${ }^{13}$ felt the presence of this property to be advantageous to the test the reality of this contamination may have caused responses such as the following:

$\begin{array}{ll}\text { Stimulus: washtub } & \text { Response: washtime } \\ \text { Stimulus: batboy } & \text { Response: badboy }\end{array}$

The writer suggests that in the absence of the non-competing syllables, the SSW might be a 'truer' dichotic task.

A further factor to consider is that in a dichotic task, when stimuli contrast by one phoneme, the REA occurs, ${ }^{21}$ but the competing syllables in Katz's SSW differ in a multiplicity of phonemes. Further, if a dichotic pair share no features, performance of normals and left-and right brain damaged subjects is similar. ${ }^{21}$ Thus the importance of phonetic control in dichotic testing is highlighted.

3. Three out of five subjects of both Group $\mathrm{E}$ and Group $\mathrm{C}$ presented with scores inferior to the average score $(0,8)$ reported for an American group of comparable age on List 1B of the SSW - a predecessor of List EC, ${ }^{14}$ with three Ss in Group $E$ and one $S$ in Group $C$ falling more than one standard deviation from this average. This highlights the necessity of a South African standardization of the SSW.

4. Error trends on the SSW were considered for all the Ss as a group. It would have been of value to compare error trends between the groups in view of the finding that dominance for vowels and consonants differs between stutterers and non-stutterers. ${ }^{32}$ 
Trends observed included:

(a) Reversals: (This is not considered an error ${ }^{14}$ ).

If the stimulus sequence is Right Non Competing (RNC), Right Competing (RC) and Left Competing (LC), Left Non Competing (LNC), the response sequence in a reversal is LC-LNC-RNC-RC. If one word leads another by $30-90$ msecs, the latter word is perceived more clearly - this is known as the "lag effect' 16 and may have intervened in reversal responses.

(b) Omissions of both or either competing syllable:

Faulty attention, storage or output have been postulated as the cause hereof. ${ }^{21}$ The writer contends that the additional processes of perception and integration may intervene.

(c) Portmanteau Terms:

The competing stimuli were combined to form a single word, e.g.

Stimulus: (RC) white (LC) foot

Response: fight

It has been suggested that on dichotic tests, errors produced by the dominant ear are the result of the interaction between the dominant and non-dominant ears. ${ }^{28}$ It is important to remember that in the SSW an REA for competing stimuli occurred.

(d) Substitutions, Additions and Omissions:

Competing Condition:

(i) Vowel substitutions resulting in a non-meaningful spondee.

(ii) Additions, omissions or substitutions of a consonantal phoneme resulting in a meaningful spondee.

(iii) Additions, omissions or substitutions of a consonantal phoneme resulting in a nonmeaningful spondee.

(iv) Substitution of a syllable (possibly more familiar) resulting in a meaningful spondee.

Non-Competing Condition:

Fewer errors occurred on non-competing conditions - nevertheless substitutions; omissions and additions of consonants and vowels were noted.

From the above observations, it is evident that an in-depth analysis of errors on the SSW would entail not only phonemic but semantic considerations. The intervention of both these systems contaminates the dichotic task, as responses are not merely based on integration and storage abilities. The use of dichotic nonsense syllables may have eliminated this contamination ${ }^{16}$ although this, too, could involve unaccountable variables. ${ }^{13}$ The proposed central auditory test could utilize in dichotic presentation, stops (which are better identified, normally, in the right ear). / a / which shows right ear superiority and / $\mathrm{i} /$ which does not. ${ }^{16}$ The utilization of right dominant sounds is hypothesized to be sensitive to left temporal lobe functioning. 
The SSW does incorporate a temporal element and includes the aspect of storage, which is important in central testing. ${ }^{26,28}$ Nevertheless, it has been suggested that sentence use assesses the temporal nature of speech to a greater extent than word use. ${ }^{29}$ It is important to bear in mind that temporal sequence perception is a function of the dominant hemisphere. ${ }^{3}$ In a natural sentence. however, two or three 'key words' may convey the sentence's meaning. To overcome this problem in auditory testing, the Synthetic Sen. tence Identification Test (SSI) was devised. ${ }^{29}$ In utilizing these sentence types in central auditory testing, a competing speech message was introduced, and it was concluded that the SSI presented with a contralateral competing message (SSI-CCM) is sensitive to temporal lobe lesions, while the SSI presented with an ipsilateral competing message (SSI-ICM) is sensitive to brainstem lesions. ${ }^{11}$ Familiar words were used however and the writer suggests that some probability factors may thus intervene in their perception. It is thus felt that a test containing strings of nonsense words presented dichotically should be considered, as the use of dichotic sentences with limited redundancy and controlled semantic value in central testing has been stressed. ${ }^{3}$

Further factors which could account for the similar performance of the stutterers and nonstutterers in this study concern the 'nature' of stuttering, and include:

1. The possible existence of sub-populations of stutterers. ${ }^{25,} 33$

2. The possibility of cerebral involvement other than temporal lobe or brainstem impairment, e.g. apraxia ${ }^{8}$, pyknolepsy ${ }^{34}$ or minimal cerebral dysfunction. ${ }^{24}$

3. The possibility of audiological involvement other than central impairment in stutterers, e.g. differing middle ear functioning ${ }^{7}$ or disturbed auditory monitoring. ${ }^{19}$

4. The possible aspects of validity of the emotional or behavioural theories of stuttering which have been postulated.

\section{CONCLUSION}

The performance of stutterers and non-stutterers on PB CID W-22 Auditory Lists with ipsilateral and contralateral masking at Signal to Noise ratios of $0 \mathrm{~dB}$ and $-10 \mathrm{~dB}$ and on the SSW were not significantly different. These results suggest the comparable functioning of the Ss on the tests utilized.

In accounting for these findings, the possibility of faults inherent in these tests, or of impairment in stutterers other than that of central auditory processes, must be considered. Bearing in mind, however, the report of inferior performance of stutterers on the SSI-ICM ${ }^{31}$ and the importance of the utilization of a test battery in audiological assessment, ${ }^{35}$ the inclusion of the SSI-ICM for brain-stem lesions and the use of either the SSI-CCM or dichotic nonsense word sentences might have led to differential responses in the sub. jects. 


\section{REFERENCES}

1. Balas, R. and Simon, G. (1964): The Articulation Function of a Staggered Spondaic Word List for a Normal Hearing Population. J. Aud. Res., 4, 285.289.

2. Berger, K. W. (1971): Speech Audiometry. In Audiological Assessment, Rose, D. E. (Ed). Prentice-Hall Inc., N. J.

3. Berlin, C. I. and Lowe, S. S. (1975): Temporal and Dichotic Factors in Central Auditory Testing. In Handbook of Clinical Audiology, Katz, J. (Ed). The Williams and Wilkins Co., Baltimore.

4. Bloodstein, O. (1969): A Handbook on Stuttering. National Easter Seal Society for Crippled Children and Adults, Chicago.

5. Bocca, E. and Calearo, C. (1963): Central Hearing processes. In Modern Developments in Audiology, Jerger, J. (Ed). Academic Press Inc., New York.

6. Brunt, M. A. (1975): The Staggered Spondaic Word (SSW) Test. In Handbook of Clinical Audiology, Katz, J. (Ed). The Williams and Wilkins Co., Baltimore.

7. Butler, B. R. and Stanley, P. E. (1966): The Stuttering Problem considered from an Automatic control point of view. Folia Phoniat., 18, 33-44.

8. Caplan, L. (1970): An Investigation of some aspects of Stuttering-like Speech in Adult Dysphasic Patients. Unpublished Research Report, Department of Speech Pathology and Audiology, University of the Witwatersiand, Johannesburg.

9. Dorman, M. F. and Porter, R. J. Jr. (1975): Hemispheric Lateralization for Speech Perception in Stutterers. Cortex, 11(2), 181-185.

10. Findlay, R. C. and Schuchman, G. I. (1976): Masking level difference for Speech: Effects of Ear Dominance and Age. Audiology, 15(3), 232. 241.

11. Jerger, J. (1973): Diagnostic Audiometry. In Modern Developments in Audiology, Jerger, J. (Ed). Academic Press, New York.

12. Johnson, W., Darley, F. L. and Spriestersbach, D.C. (1963): Diagnostic Methods in Speech Pathology. Harper and Row, New York.

13. Katz, J. (1962): The use of Staggered Spondaic Words for Assessing the Integrity of the Central Auditory Nervous System. J. Aud. Res., 2, 327.337.

14. Katz, J. (1968): The SSW Test: An Interim Report. J. Speech Hear. Dis., 33(2), 132.146.

15. Kimura, D. (1967): Functional dominance of the brain in dichótic listening. Cortex, 3(2), 163.178.

16. Lowe, S. S., Cullen, J. K. Jr., Berlin, C. I., Thompson, C. L. and Willett, M. E. (1970): Perception of Simultaneous Dichotic and Monotic Monosyllables. J. Speech Hear. Res., 13(4); 812-822.

17. Luria, A. R. (1973): The Working Brain. The Penguin Press, London.

18. Milner, B. (1962): Laterality Effects in Audition. In Interhemispheric Relations and Cerebral Dominance, Mountcastle, V. B. (Ed). The John Hopkins Press, Baltimore. 
19. Mysak, E. D. (1960): Servo Theory and Stuttering. J. Speech Hear Dis., 25(2), 188-195.

20. Newby, H. A. (1972): Audiology. Prentice-Hall Inc., New Jersey.

21. Oscar-Berman, M., Zurif, E. B. and Blumstein, S. (1975): Effects of Unilateral Brain Damage on the Processing of Speech sounds. Brain and Lang., 2(3), 345-355.

22. Penfield, W. and Roberts, L. (1959): Speech and Brain Mechanisms. Princeton University Press, New Jersey.

23. Radionova, E. A. and Vartanian, I. A. (1971): Comparative Description of the Characteristics of Normal Activity at Different Levels of the Auditory System. J. Aud. Res., 11(3), 195-217.

24. Saffer, D. (1976): Personal Communication. Neurologist, Baragwanath Hospital, Johannesburg.

25. Sander, E. K. (1975): Untangling Stuttering. A tour through the theory thicket. Asha, 17(4), 256.

26. Satz, P., Achenbach, K., Pattishall, E. and Tennell, E. (1965): Order of report, ear asymmetry and handedness in dichotic listening. Cortex, 1(4), 377.396.

27. Slorach, N. and Noehr, B. (1973): Dichotic listening in Stuttering and Dyslalic Children. Cortex., 9(3), 295-300.

28. Speaks, C., Gray, T., Miller, J. and Rubens, A.B. (1975): Central Audjtory Deficits and Temporal Lobe Lesions. J. Speech Hear. Dis., 40(2), 192-205.

29. Speaks, C. and Jerger, J. (1965): Method for measurement of Speech Identification. J. Speech Hear. Dis., 8(2), 185-194.

30. Timmons, B. A. and Boudreau, J. P. (1972): Auditory Feedback as a Major Factor in Stuttering. J. Speech Hear. Dis., 37(4), 476.484.

31. Toscher, M.M. and Rupp, R. R. (1975): A study of the Central Auditory Processes in Stutterers using the Synthetic Sentence Identification (SSI) Test Battery. Asha, 17(9), 680.

32. Tsunoda, T. and Moriyana, H. (1972): Specific Pattern of Cerebral Dominance for various sounds in adult stutterers. J. Aud. Res., 12(3), 216-227.

33. Van Riper, C. (1971): The Nature of Stuttering. Prentice-Hall Inc., New Jersey.

34. West, R. (1958): An Agnostic's Speculations upon Stuttering. In Stuttering: $\boldsymbol{A}$ Symposium, Eisenson, J. (Ed). Harper and Row, New York.

35. Willeford, J. A. (1969): Audiological Evaluation of Central Auditory Disorders Part II. Maico Audiological Library Series, 6, 5-7.

36. Willis, C. (1975): Stuttering and aphasia: some important similarities and some important differences. WMU J. of Sp. Th., 12(1), 11.12.

37. Young, I. 'M. and Harbert, F. (1970): Noise Effects on Speech Discrimination Score. J. Aud. Res., 10(2), 127-131. 